\title{
Clearance of Renin in Unanesthetized Rats: Effects of Chronic Lead Exposure ${ }^{1}$
}

\author{
JOAN A. KeISER, ${ }^{2}$ ARTHUR J. VANDER, ${ }^{3}$ AND CAROL L. GERMAIN \\ Department of Physiology. The University of Michigan Medical School, Ann Arbor, Michigan 48109
}

Received January 31, 1983; accepted February 19, 1983

\begin{abstract}
Clearance of Renin in Unanesthetized Rats: Effects of Chronic Lead Exposure. KEISER, J. A., Vander, A. J., AND Germain, C. L. (1983). Toxicol Appl. Pharmacol. 69, 127-137. These experiments studied the influence of chronic lcad exposure on the steady-state clearance of exogenous homologous renin in unanesthetized, unrestrained rats. Relative to time controls (TC), rats chronically exposed to $500 \mathrm{ppm}$ lead in drinking water had significantly elevated basal plasma renin concentrations $(\mathrm{PRC})(\mathrm{Pb}=12.0 \pm 1.6 \mathrm{ng} / \mathrm{ml} / \mathrm{hr}, \mathrm{TC}=7.6 \pm 0.8)$. During the infusion of homologous renin sufficient to increase plasma renin approximately 10 -fold, the clearance of renin was not different between the two groups (after 60 -min infusion, $\mathrm{Pb}=16.1 \pm 1.8 \mathrm{ml} / \mathrm{kg} /$ $\min , \mathrm{TC}=15.9 \pm 1.5$ ). Rats exposed to $1000 \mathrm{ppm}$ lead did not have higher PRCs than time controls $(\mathrm{Pb}=10.9 \pm 2.2, \mathrm{TC}=9.2 \pm 1.8)$. The clearances of renin in these two groups were also not significantly different $(\mathrm{Pb}=15.3 \pm 2.8, \mathrm{TC}=18.3 \pm 2.5)$. Renal renin concentrations were significantly elevated in the $500 \mathrm{ppm}$ rats $(\mathrm{Pb}=1426 \pm 110 \mathrm{ug} / \mathrm{kidney}, \mathrm{TC}=1065 \pm 118)$ consistent with an increased basal renin secretion, but were not elevated in the 1000 -ppm rats. There were no significant differences in the clearances of sulfobromophthalein (BSP) between any of the groups. The renin infusion significantly reduced BSP clearance, but did so equally in all groups. It is concluded that in unanesthetized, unrestrained rats the clearance of renin is not altered by chronic lead exposure of either 500 or $1000 \mathrm{ppm}$ and that increased secretion of renin accounts for the elevated basal PRC observed in rats exposed to the lower dose of lead.
\end{abstract}

Acute exposure of rats and dogs to iv administered lead is associated with an increase in plasma renin activity (PRA) (Goldman et al., 1981; Mouw et al., 1978). Chronic lead exposure $(500 \mathrm{ppm}$ in drinking water, started at 5 to 6 weeks of age) also produces significant elevations of PRA and plasma renin concentration (PRC) in rats (Fleischer et al., 1980; Victery et al., 1982a), with no change in plasma angiotensinogen concentration. It has

\footnotetext{
' This work was supported by NIOSH Grant 5R01 OH 00913.

${ }^{2}$ This work was done in partial fulfillment of requirements for the PhD degree by J. A. Keiser. Current address: Department of Physiology and Biophysics, Mayo School of Medicine, University of Minnesota, Rochester, Minn. 55905.

${ }^{3}$ To whom requests for reprints should be addressed.
}

been demonstrated that the increased PRA observed in dogs following acute administration of lead is a result of decreased hepatic removal of renin with little or no change in renin secretion (Goldman et al., 1981). Hence, it is possible that the increase in PRC observed in the chronic lead-exposed rat is also due, at least in part, to a decreased rate of renin removal from plasma.

We have recently tested this hypothesis in rabbits (Keiser et al., 1983) by determining the effects of chronic $\mathrm{Pb}$ exposurc on the halflife of renin following nephrectomy. These data provided no evidence that renin clearance was altered by chronic lead exposure. However, these experiments were complicated by the fact that the $\mathrm{Pb}$-exposed rabbits, unlike rats, failed to show a rise in PRA and 
by the requirements for anesthesia, surgery, nephrectomy, and non-steady-state conditions. These are the usual methods for evaluating renin clearance in small animals (Christlieb et al., 1968; DeVito et al., 1974; Michelakis and Mizukoshi, 1971; Schneider et al., 1970) despite evidence that these procedures can profoundly lower hepatic blood flow (Birnie and Grayson, 1952) and that removal of renin by the liver accounts for virtually $100 \%$ of renin clearance (Heacox et al., 1967; Horky et al., 1970). Therefore, the present experiments utilized unanesthetized, unrestrained rats and studied the steady-state clearance of homologous renin (achieved by renin infusions). The plasma concentrations of renin were sufficiently elevated to render trivial any contribution of endogenous renin secretion.

\section{METHODS}

All experiments were performed on adult male rats obtained from Charles River (Wilmington, Mass.). The animals were housed in a temperature-controlled room $\left(24^{\circ} \mathrm{C}\right)$ on a fixed light schedule $(0600-1800)$. They had free access to water and were fed ad libitum with a standard rat chow (Purina Rat Chow, No. 5012).

\section{Protocol 1. Clearance of Renin in Chronically Lead-Ex- posed and Control Rats}

Series $A$. Thirty-six male rats (initially approximately $150 \mathrm{~g}$ ) were randomly divided into two treatment groups. The first group $(n=18)$ was given $500 \mathrm{ppm}$ lead as lead acetate in the drinking water for 14-15 weeks, at which time clearance experiments were performed as described below. The second group of rats $(n=18)$ served as agematched time-controls and drank tap water.

Series $B$. Twenty four male rats (initially approximately $150 \mathrm{~g}$ ) were randomly divided into two treatment groups. The first group $(n=12)$ were given $1000 \mathrm{ppm}$ lead as lead acetate in their drinking water for 15 to 16 weeks. The second group $(n=12)$ served as time-controls and drank tap water.

The day before the clearance experiment was to be performed, each rat was anesthetized with sodium pentobarbital $(50 \mathrm{mg} / \mathrm{kg}$, ip). Heparinized catheters were inserted into the left jugular vein and carotid artery for infusion and sampling, respectively; the catheters were exteriorized from the dorsal cervical region of the neck. The next morning patency of the catheters was ascer- tained and any animal from whom a blood sample could not bc obtaincd was excluded from the experiment. Previous pilot studies had demonstrated that, in hydrated rats, by the first morning postsurgery, basal plasma renin was unchanged from that of unoperated animals. The experiment consisted of a 90-min infusion period; rats were unanesthetized and unrestrained in individual wirefimored cages during the protocol. Coiled connectors (PE50 tubing) were attached to the venous and arterial catheters, allowing for the collection of blood samples without handling the animals. Blood samples $(400 \mu \mathrm{l})$ were obtained at $0,30,75$, and $90 \mathrm{~min}$ via the arterial line, which was otherwise used for continuous pressure recording. After the initial (0) blood sample, an infusion of BSP (Sigma Chemical Co., St. Louis, Mo., No. S 0252) was initiated. The priming dose of BSP was $17.5 \mathrm{mg} / \mathrm{kg}$ in $0.2 \mathrm{ml}$ followed by a constant infusion of $0.63 \mathrm{mg} / \mathrm{kg}$ min given at $0.02 \mathrm{ml} / \mathrm{min}$ with a Harvard infusion pump. After a 30 min blood sample for BSP clearance determination had been obtained, the BSP was continued and renin (semipurified, homologous renin ${ }^{4}$ ) was begun $(500 \mathrm{ppm}$ rats and their time-controls received a priming dose of 12.4 $\mu \mathrm{g} / \mathrm{kg}$ and a constant infusion of $1240 \mathrm{ng} / \mathrm{kg} / \mathrm{min} ; 1000-$ ppm rats and their controls received a priming dose of $18.9 \mu \mathrm{g} / \mathrm{kg}$ and a constant infusion of $1890 \mathrm{ng} / \mathrm{kg} / \mathrm{min}$ ). Blood samples were obtained again at 75 and $90 \mathrm{~min}$ for determination of BSP and renin. In a fraction of the animals a sample was also obtained at $105 \mathrm{~min}$. In four animals (two TC, two $500 \mathrm{ppm}$ ), after completion of the usual clearances, the infusion of renin was reduced by $50 \%$, and additional clearance measurements were made 45 and 60 min later. In addition to BSP and renin, plasma angiotensin II (AII) was also measured in the final blood sample obtained in all experiments.

At the completion of the clearance experiments animals were killed by iv administration of $100 \mathrm{mg} / \mathrm{kg}$ sodium pentobarbital. Both kidneys were rapidly excised, rinsed with ice-cold saline, dried, weighed, and frozen for later analysis.

\section{Protocol 2. Effects of Renin Infusion on the Clearance of BSP}

Another study was performed on normal rats to examine the time course of the clearance of BSP with and without the additional infusion of renin. Fourteen male rats $(365 \mathrm{~g})$ were randomly divided into two treatment groups. The clearance experiments werc identical to those described above except that the first group $(n=7)$ received BSP infusions alone throughout the $90 \mathrm{~min}$. The second group $(n=7)$ received BSP for the first $30 \mathrm{~min}$ and BSP with renin for an additional hour. Samples were collected as described above.

\footnotetext{
${ }^{4}$ Semipurified rat renin was generously provided by Dr. Erwin Haas.
} 


\section{Protocol 3. Angiotensin II Infusion}

A necessary assumption made in our calculation of renin clearances was that the only source of renin in the rats during the protocol was the exogenous renin infused. As will be described below, the plasma concentrations of renin achieved were approximately 10 -fold greater than basal concentrations so as to minimize the contribution of endogenous renin. Moreover, it was expected that endogenous renin would fall below basal concentrations during renin infusions, because AII is a potent inhibitor of renin secretion, and plasma AII concentrations were markedly elevated by the renin infusions. This assumption was tested by infusing AII into rats and measuring PRC. Three normal rats were instrumented as previously described. After baseline pressure recordings and blood samples had been obtained, the rats were infused with All (Beckman; synthetic AII, lot No. 337707) at $15 \mathrm{ng} /$ $\mathrm{kg} / \mathrm{min}$; additional blood samples were obtained at 45 and $60 \mathrm{~min}$ for measurement of PRC. Plasma AII concentrations were measured on the $60-\mathrm{min}$ sample.

\section{Analvical Methods}

Blood samples were collected in tubes containing 0.01 $\mathrm{ml}$ of $0.2 \mathrm{M}$ disodium ethylenediaminetetraacetate (NaEDTA); samples for measurement of AII were collected in an anticoagulant/inhibitor mixture containing $0.125 \mathrm{M}$ NaEDTA and $0.025 \mathrm{M} \sigma$-phenathrolline in distilled water with $0.2 \%$ neomycin sulfate. Samples were chilled, centrifuged, and separated at $4^{\circ} \mathrm{C}$, and the plasma was frozen for subsequent analysis.

Hematocrit was measured on a microhematocrit reader after centrifugation in a microcapillary centrifuge for 5 min. Plasma $\mathrm{Na}^{+}$and $\mathrm{K}^{+}$concentrations were determined by flame photometry. Blood lcad was mcasured by graphite furnace atomic absorption (Varian Instruments, Model 375 CRA 90) by methods of addition. Standard spectrophotometric techniques were used to measure BSP (Seligson et al., 1957), with a modification for microsamples. AII was measured by direct radioimmunoassay of arterial plasma according to the methods of Nicholls and Espiner ${ }^{5}$ (1976). PRA was measured by radioimmunoassay of generated angiotensin I with some modifications of a commercially available kit (New England Nuclear Corp., Boston); the assay has been described in detail previously (Mouw et al., 1978). Renal renin concentration was determined on homogenates of renal tissue after appropriate dilution and addition of substrate from 48-hr nephrectomized rat plasma.

To make the calculation of renin clearance, it was necessary to convert PRA into PRC, since animals have a range of substrate concentrations (and, possibly, endog-

\footnotetext{
${ }^{5}$ The authors gratefully acknowledge the generous stock of AII antibody supplied to us by M. Gary Nicholls.
}

enous inhibitors or activators of the reaction), which would contribute to variability in the measure of PRA at any given concentration of renin. Therefore, we converted activity to concentration in individual animals in the following manner. First, a plasma renin "increment" was measured in at least one plasma sample from each rat by the addition of a standard amount of homologous renin to the samples; the additional amount of AI generated above baseline was labeled the increment. A mean value $(\bar{X})$ for the increments was obtained for the group of rats, and the plasma renin concentration (PRC) for an individual rat (i) was calculated:

$$
\operatorname{PRC}=\operatorname{PRA} \frac{(\bar{X} \text { increment })}{(i \text { increment })} .
$$

The mean increment was also used to calculate the concentration of homologous renin given to the rats. The mean increments were similar in all groups of rats confirming that lead does not alter the relationship between PRA and PRC (Fleischer et al., 1980; Mouw et al., 1978). The clearance of renin was calculated as the mass infused per minute divided by the PRC, and was expressed as $\mathrm{ml} / \mathrm{kg} / \mathrm{min}$. The analogous formula was used to calculate the clearance of BSP.

\section{Statistical Analysis}

All group values are means $\pm 1 \mathrm{SE}$. Student's $t$ test was used to test the difference between the two group means. A paired $t$ test was used to compare data before and after treatments within a group. A $p$ value less than 0.05 was accepted as significant.

\section{RESULTS}

\section{Protocol 1. Clearance of Renin in Chronically Lead-Exposed and Control Rats}

In rats chronically treated with $500 \mathrm{ppm}$ lead, the basal PRC (obtained $30 \mathrm{~min}$ into the experiment) was approximately $60 \%$ higher than that of age-matched controls $(\mathrm{Pb}=12.0$ $\pm 1.6 \mathrm{ng} / \mathrm{ml} / \mathrm{hr}, \mathrm{TC}=7.6 \pm 0.8, p<.05$ ). These data are depicted in Fig. 1 along with basal PRCs in the 1000-ppm rats and their controls. Although some of the rats treated with $1000 \mathrm{ppm}$ lead had high basal PRCs, the mean value for the group was not significantly different from that of controls $(\mathrm{Pb}=10.9$ $\pm 2.2, \mathrm{TC}=9.2 \pm 1.8$ )

Figure 2 depicts the PRCs achieved during the renin infusions in the two series. The renin 
A

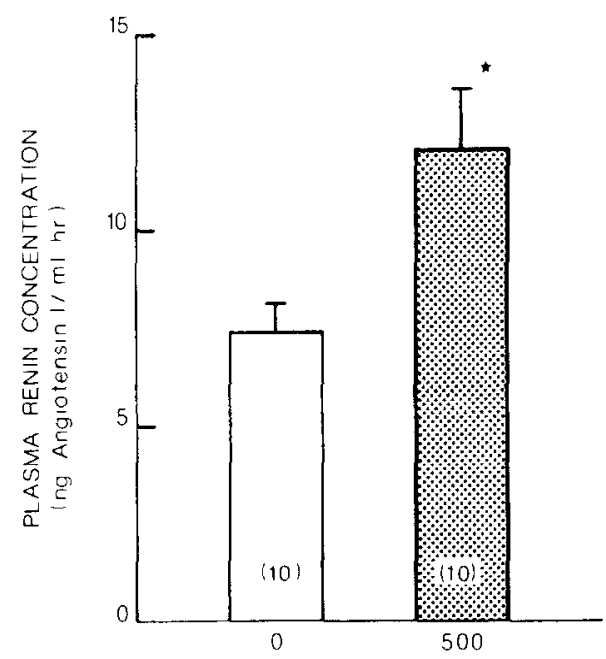

DOSE
B

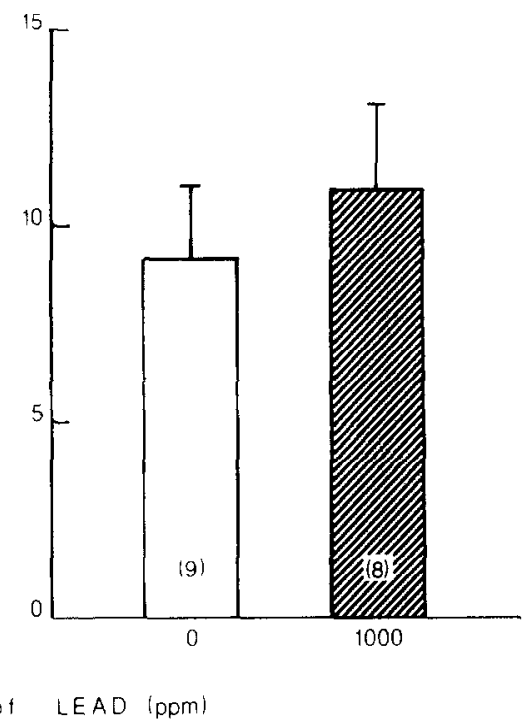

FIG. 1. Effect of chronic lead exposure on basal plasma tenin concentrations (PRC). The PRC was significantly elcvated $(p<0.05)$ in rats exposed to $500 \mathrm{ppm}$ lead in drinking water.

infusions produced an 8- to 10-fold elevation in PRCs above basal levels. Values achieved for time-control and treatment groups were similar in both series. In a small number of rats from each group, renin infusions were maintained for an additional $15 \mathrm{~min}$, and these values are also shown in Fig. 2; it is clear that steady-state values for PRC have been achieved by 75 to 90 mins.
The clearances of renin are depicted in Fig. 3 ; at no time were there any significant differences between the lead-treated rats and their time-control groups. The mean clearance was $14.7 \pm 1.6 \mathrm{ml} / \mathrm{kg} / \mathrm{min}$ in the $500 \mathrm{ppm}$ rats at $75 \mathrm{~min}$ and $13.9 \pm 1.4$ in the age-matched controls. Values for the $1000-\mathrm{ppm}$ rats and time-controls at $75 \mathrm{~min}$ were $14.4 \pm 2.2$ and $17.0 \pm 2.6 \mathrm{ml} / \mathrm{kg} / \mathrm{min}$, respectively. The 90 -

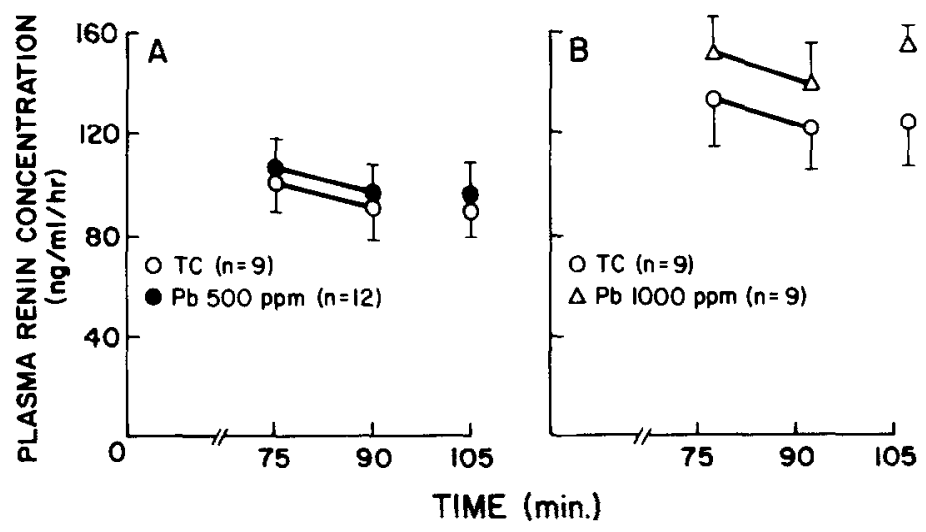

FIG. 2. Plasma renin concentrations achieved during infusion of exogenous homologous renin. Renin infusions were initiated $30 \mathrm{~min}$ into the protocol. The 1000 -ppm rats and their time controls (TC, series B) received a 50\% larger renin infusion than did the series $\mathrm{A}$ animals. In a fraction of the rats from each group, samples were also obtained at $105 \mathrm{~min}$; therefore, the 90- and 105-min points are not connected. 


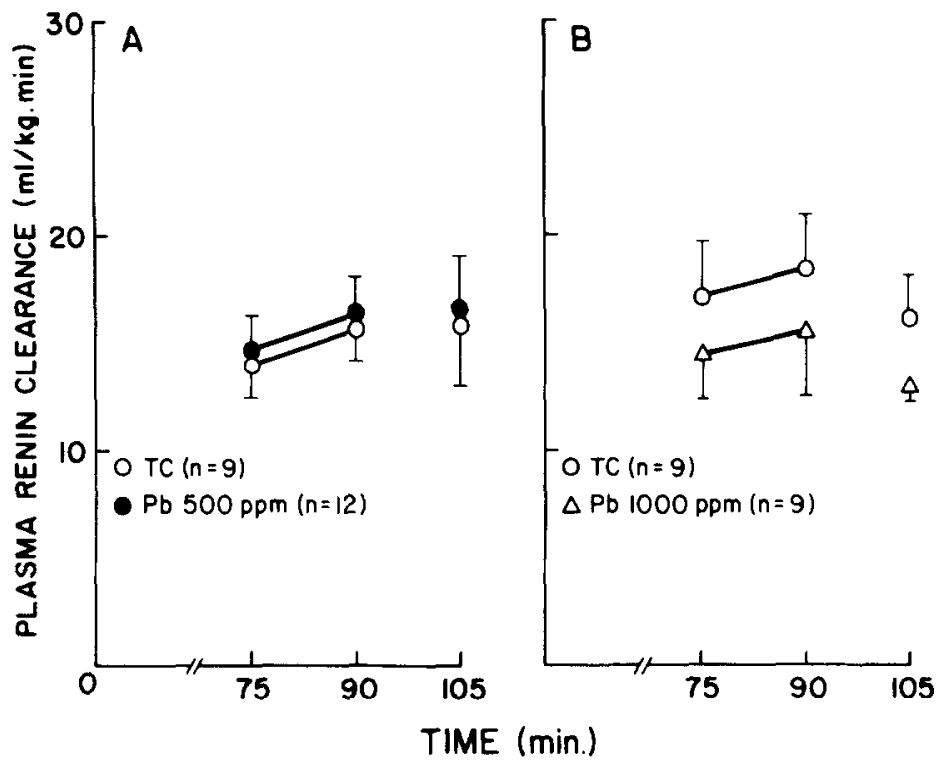

FIG. 3. Clearance of renin in two series of chronically lead-exposed rats and time controls (TC). In a fraction of the rats from each group, clearances were also measured on samples obtained at $105 \mathrm{~min}$; therefore, the 90 - and $105-\mathrm{min}$ points are not connected.

and $105-$ min clearances were similar to values observed at $75 \mathrm{~min}$.

Clearances of BSP before and during renin infusions are shown in Fig. 4. The 500-ppm rats had average BSP clearances of $26.5 \pm 2.1$ $\mathrm{ml} / \mathrm{kg} / \mathrm{min}$ at $30 \mathrm{~min}$; the controls averaged $25.5 \pm 2.5$. There was a significant drop in the clearance of BSP within each group be- tween 30 and $75 \mathrm{~min}$, the values at $75 \mathrm{~min}$ being approximately $30 \%$ lower. There were no significant differences in the clearance of BSP between the two groups at any time during the experiment. The same pattern was seen for BSP clearance data from the 1000-ppm rats and their controls, shown in Fig. 2B. Clearances ranged from 23 to $25 \mathrm{ml} / \mathrm{kg} / \mathrm{min}$
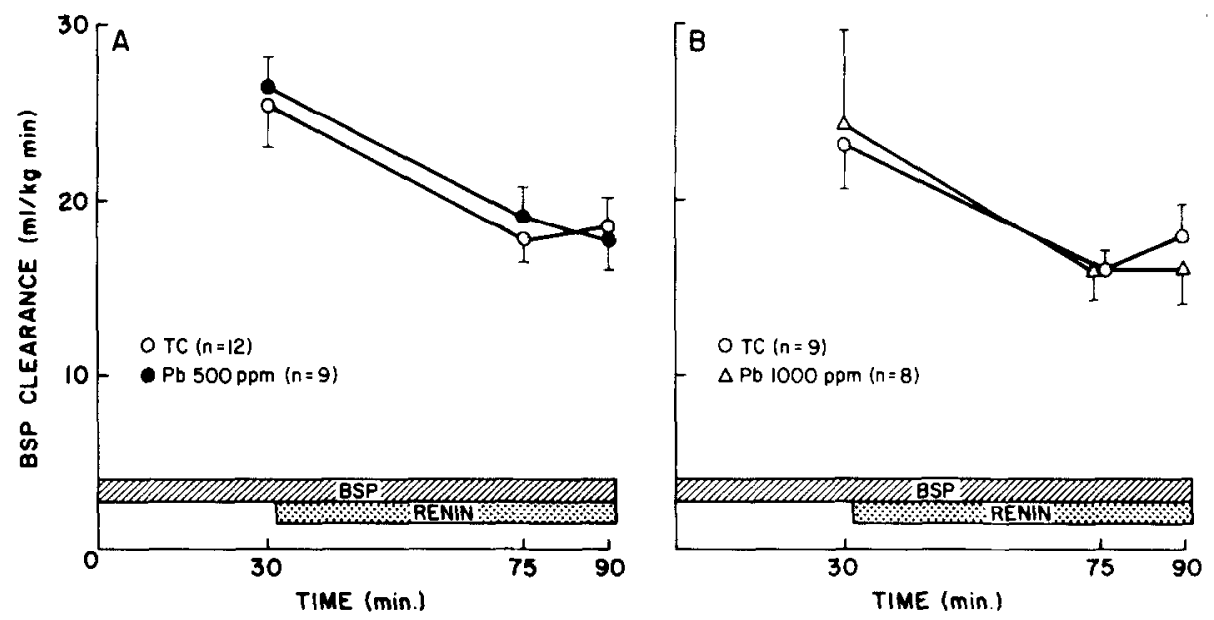

FIG. 4. Clearance of BSP hefore and during infusion of renin in two series of Ph-exposed and timecontrol (TC) rats. The clearance of BSP fell significantly within each group of rats between 30 and $75 \mathrm{~min}$. 
at $30 \mathrm{~min}$, dropped approximately $35 \%$ in both groups between 30 and $75 \mathrm{~min}$ and remained stable throughout the remainder of the experiment.

Plasma AII concentrations did not differ between the lead-treated groups and their controls: $500 \mathrm{ppm} \mathrm{Pb}=162.7 \pm 21.1 \mathrm{pg} / \mathrm{ml}$, $\mathrm{TC}=154.9 \pm 21.9 ; 1000 \mathrm{ppm} \mathrm{Pb}=181.6 \pm$ 13.6, $\mathrm{TC}=157.2 \pm 17.6$. Figure 5 depicts the correlation $\left(r^{2}=0.77\right)$ between plasma renin activity and AII concentrations from both control groups (pooled, $n=19$ ); the blood samples were drawn at the end of the clearance experiments. (PRA, rather than PRC, was used for this correlation, since it is with activity rather than concentration that AII should correlate best). The graph also includes the 500- and 1000-ppm rat data, which are not included in the calculation of the regression line. The slope of the regression line derived from control rat data is 1.63; those for the 500-ppm $\left(r^{2}=0.72, n=14\right)$ and 1000ppm $\left(r^{2}=0.76, n=9\right)$ rats yield slopes of 1.49 and 1.10 , respectively. It is clear from the figure that the points for the 500 -ppm rats scatter along the regression line, whereas eight of the nine 1000-ppm points fall below the control regression line.
Renal renin concentrations in the four groups of rats are shown in Fig. 6. Rats chronically treated with $500 \mathrm{ppm}$ lead had renal renin concentrations that were significantly different from their age matched controls $(1426 \pm 110$ vs $1065 \pm 118)(p<0.05)$. The elevation in renin concentrations observed in the 500-ppm rats was not present at the 1000 ppm dose; rats exposed to $1000 \mathrm{ppm}$ lead had a mean renal renin concentration of 1089 $\pm 132 \mu \mathrm{g} / \mathrm{kidney}$, whereas the control level was $1069 \pm 93$.

Blood lead, hematocrit, weight, and plasma electrolyte data from the four groups of rats are reported in Table 1. Blood lead concentrations were $41.3 \pm 2.3 \mu \mathrm{g} / \mathrm{dl}$ in the $500-\mathrm{ppm}$ rats and $54.9 \pm 1.9$ in the 1000 -ppm rats. Body weights were similar within each agematched series. Kidney weights tended to be higher (although not significantly) in the 500ppm rats compared to their controls, but the trend was not apparent at $1000 \mathrm{ppm}$ lead.

In four animals (two TC, two $500 \mathrm{ppm}$ ), after completion of the BSP and renin clearances, the infusion of renin was reduced by $50 \%$ and additional clearance measurements were made 45 and 60 min later. In Fig. 7 the relationship between PRC and renin clear-

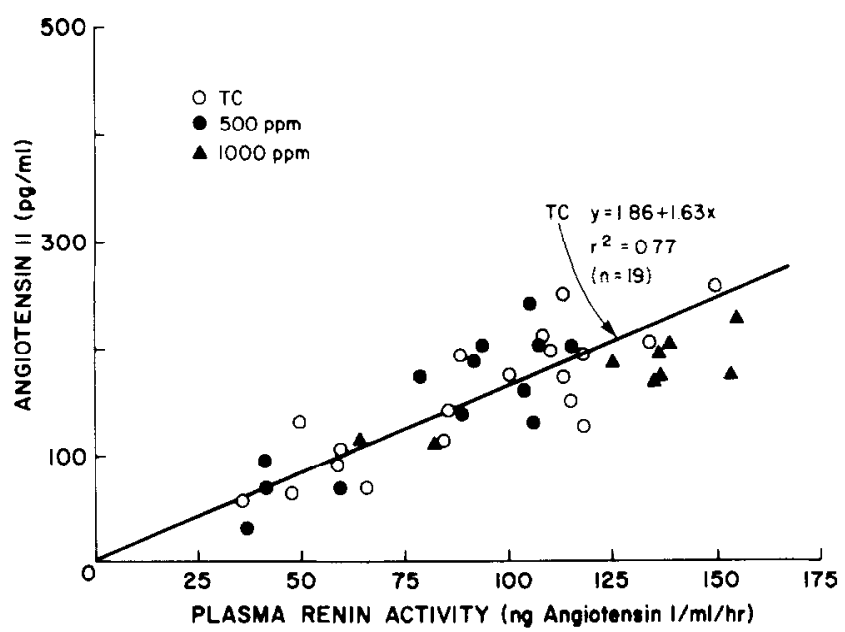

FIG. 5. Correlation between plasma renin activity and angiotensin II concentration in time control (TC, pooled) and lead-exposed (500 and $1000 \mathrm{ppm}$ ) rats during renin infusion. The regression line was calculated only for the time-control animals. 


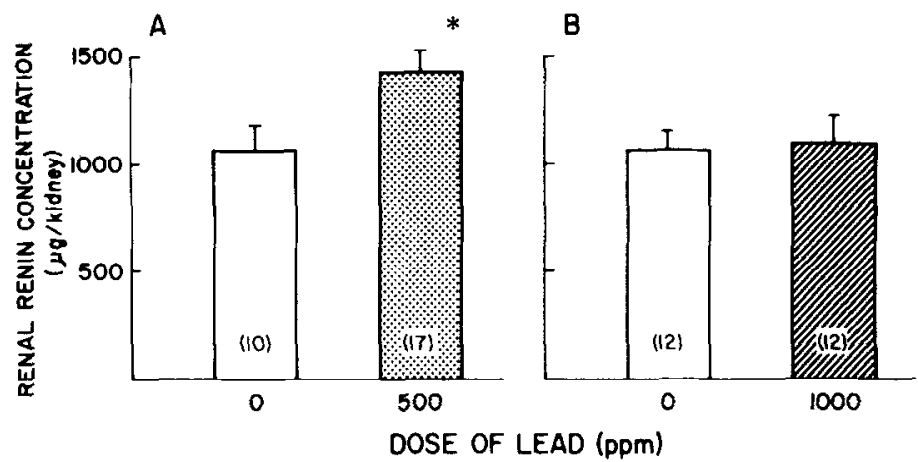

FIG. 6. Effects of lead on renal renin concentration in two series of animals. Rats chronically exposed to $500 \mathrm{ppm}$ lead had a significant elevation $(p<.05)$ compared to time controls.

ances is depicted for this group of four rats and contrasted with data from the other rats in that series (series A). The clearances of renin were quite similar in the two groups despite a two-fold range of plasma renin concentrations.

\section{Protocol 2. Effect of Renin Infusion on the Clearance of $B S P$}

The clearance of BSP was measured in a series of acute rats with and without the additional infusion of renin. In the group of rats that received renin and BSP, the clearance of
BSP at 75 min dropped significantly to 69.4 $\pm 3.1 \%$ of the baseline measured at $30 \mathrm{~min}$. Rats receiving BSP alone also showed a fall in BSP clearance between 30 and $75 \mathrm{~min}$, but of a much smaller magnitude; the value at 75 $\min$ was $87.3 \pm 5.8 \%$ of the baseline measurement; this value was significantly different from that of the renin-infused rats.

\section{Protocol 3. Angiotensin II Infusion}

Figure 8 depicts the PRCs in three rats bcfore and during constant infusions of AII (15 $\mathrm{ng} / \mathrm{kg} / \mathrm{min})$. The mean PRC at time zero was

TABLE ]

Blood lead, Hematocrit, Weights, and Plasma Electrolytes in Chronically lead-Treated Rats

\begin{tabular}{|c|c|c|c|c|}
\hline \multirow[b]{3}{*}{ Indices } & \multicolumn{4}{|c|}{ Dose of lead ${ }^{a}$ added to drinking water } \\
\hline & \multicolumn{2}{|c|}{ Series A } & \multicolumn{2}{|c|}{ Series B } \\
\hline & $\begin{array}{c}0 \\
(n=9)\end{array}$ & $\begin{array}{c}500 \\
(n=12)\end{array}$ & $\begin{array}{c}0 \\
(n=9)\end{array}$ & $\begin{array}{c}1000 \\
(n=10)\end{array}$ \\
\hline Blood [lead] $(\mu \mathrm{g} / \mathrm{dl})$ & $2.2 \pm 0.5$ & $41.3 \pm 2.3$ & - & $54.9 \pm 1.9$ \\
\hline Hematocrit $(\times 100)$ & $44.1 \pm 1.4$ & $42.8 \pm 1.3$ & $42.3 \pm 0.7$ & $40.5 \pm 1.6$ \\
\hline Body weight (g) & $512.3 \pm 12.5$ & $531.7 \pm 22.6$ & $565.5 \pm 11.1$ & $556.2 \pm 11.2$ \\
\hline Kidney weight $(\mathrm{g})$ & $1.66 \pm 0.07$ & $1.86 \pm 0.07$ & $1.79 \pm 0.07$ & $1.76 \pm 0.04$ \\
\hline Plasma $\left[\mathrm{Na}^{+}\right](\mathrm{mM})$ & $140.8 \pm 0.9$ & $141.9 \pm 1.2$ & $142.2 \pm 1.0$ & $140.9 \pm 0.5$ \\
\hline Plasma $\left[\mathrm{K}^{+}\right](\mathrm{mm})$ & $4.83 \pm 0.33$ & $4.20 \pm 0.13$ & $4.89 \pm 0.25$ & $4.87 \pm 0.22$ \\
\hline
\end{tabular}

Note. Values are mean $\pm \mathrm{SE}$. - . Not measured.

${ }^{a}$ As lead acetate. 


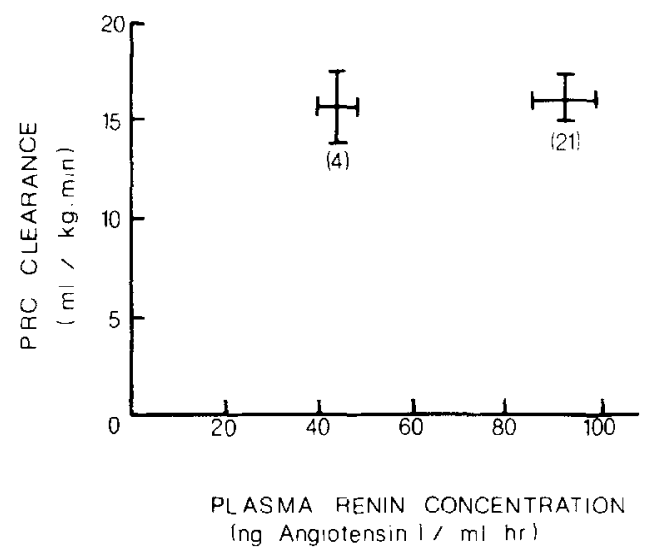

FIG. 7. Relationship between PRC and renin clearance. The group of animals with PRCs of 85 to $95 \mathrm{ng} \mathrm{Al} / \mathrm{ml} /$ hr represent the series A standard protocol. The second group of animals represent rats in which the renin infusion was reduced $50 \%$ for additional clearance measurements following the standard protocol.

$8.3 \pm 1.6 \mathrm{ng} / \mathrm{ml} / \mathrm{hr}$ and fell to $2.6 \pm 1.1$ and $2.1 \pm 0.7 \mathrm{ng} / \mathrm{ml} / \mathrm{hr}$ at 45 and $60 \mathrm{~min}$, respectively. The mean plasma AII concentration measured for the group at $60 \mathrm{~min}$ was $72.0 \pm 24.3 \mathrm{pg} / \mathrm{ml}$, a value less than that present during the renin infusions of series $A$ and B. Values for the individual animals are shown on the graph in parentheses.

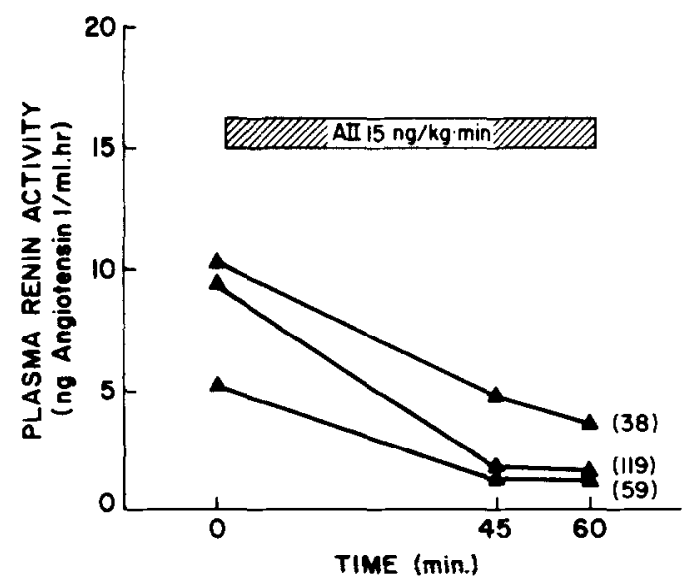

FIG. 8. Plasma renin concentrations in three rats before and during constant infusions of AII. Plasma AII concentrations $(\mathrm{pg} / \mathrm{ml})$ measured in the 60 - $\mathrm{min}$ sample are shown in parentheses for the individual animals.

\section{DISCUSSION}

The hypothesis that rats chronically exposed to lead, beginning as young adults, have decreased metabolic clearance of renin was clearly not supported by the present experiments. As in previous studies (Fleischer et al., 1980; Victery et al., 1982a), basal PRC increased significantly in the $500-\mathrm{ppm}$ leadtreated rats compared to controls; however, clearances of renin from plasma, measured during steady-state infusions of homologous renin, were not different. Therefore, the elevation in PRC must be the result of increased renin secretion; this view is further supported by the fact that renal renin concentrations were significantly elevated in the $500-\mathrm{ppm}$ rats. It has been reported that basal renin secretory rates and renal renin concentrations are well correlated in a variety of chronic physiologic states (Park et al., 1978).

Rats exposed to $1000 \mathrm{ppm}$ lead also had renin clearances that were not different from controls. However, unlike the 500 -ppm rats, these animals also failed to exhibit an elevation in plasma renin concentration. This finding is the first report of the effects of 1000 ppm lead on renin, and the discrepancy between the effects of 500 and 1000 ppm is consistent with our previous conclusions (Victery et al., 1982b) that the dose-response relationship between lead and renin is complex, consisting of both inhibitory and stimulatory components. It is likely that at the 1000 -ppm dose these opposing effects tend to cancel each other out. This view is also consistent with our recent finding of increased basal renin secretion by renal cortical slices from rabbits exposed to $500 \mathrm{ppm} \mathrm{Pb}$ with no further augmentation at $1000 \mathrm{ppm} \mathrm{Pb}$ (Keiser et al., 1983).

The present model for studying renin clearance is the classic steady-stage metabolic clearance method, but it has not previously been reported for unanesthetized rats. Such a constant infusion technique should be more accurate for assessing the rate of renin re- 
moval from plasma than are the more usual approaches involving disappearance curves following nephrectomy or bolus injections of renin. Moreover, we chose to use this unanesthetized, unrestrained rat model to eliminate the problems resulting from alterations in hepatic blood flow associated with anesthetic agents and surgical trauma (Birnie and Grayson, 1952). Infusions of exogenous homologous renin for an adequate length of time permit attainment of steady-stage conditions for the measurement of clearance. In pilot experiments with both BSP and renin infusions, steady-state plasma concentrations were achieved within 20 to $25 \mathrm{~min}$. Therefore, renin clearance measurements in the present studies were performed after at least $45 \mathrm{~min}$ of constant infusion. The stability of the clearance measurements at 45,60 , and $75 \mathrm{~min}$ after initiating renin infusions attests to the achievement of steady-state conditions.

An important assumption in these experiments is that the infusions were the sole significant source of the test substances. Since BSP does not occur naturally in rats this criterion was readily met; however, renin is, of course, secreted by rats in response to a number of stimuli, including hemorrhage. The chronic rats used in these experiments averaged 525 to $560 \mathrm{~g}$, and the blood samples drawn during the course of a protocol totaled about $1.5 \mathrm{ml}$. Thus the blood sampling that occurred amounted to approximately a $5 \%$ hemorrhage over a 90-min interval. However, it is important to note that hematocrit did not change between the first and last samples, indicating the modest nature of this hemorrhage. That endogenous renin is, in fact, not a problem in our methods is evidenced by the series of animls in which AII was infused. PRCs fell to very low values $(2.1 \pm 0.7 \mathrm{ng} /$ $\mathrm{ml} / \mathrm{hr}$ ) despite the blood sampling that occurred, even though the final plasma AII concentrations achieved by the AII infusions were only $50 \%$ of those produced by the infusions of renin. Thus, any remaining endogenous renin secretion must have been only a trivial percentage of the total renin infused per minute into the test rats (mean steady-state plasma renin achieved was approximately 100 $\mathrm{ng} / \mathrm{ml} / \mathrm{hr}$ ).

A second potential problem with the present method is its use of exogenous rather than endogenous renin. However, it has been reported that endogenous and exogenous renin is inactivated at the same rate in both dogs (Schneider et al., 1968) and rats (Peters-Haefeli, 1971; Schaechtelin et al., 1964).

Finally, it is crucial to ask whether the clearance rates at the PRC levels achieved during our infusions are an accurate reflection of the clearance of renin in the normal physiologic range of PRCs. In the group of rats in which the renin infusion dose was lowered by $50 \%$, PRCs averaged only 40 to $45 \mathrm{ng} / \mathrm{ml} / \mathrm{hr}$, but the clearance of renin was not different from rats with PRCs of 85 to $90 \mathrm{ng} / \mathrm{ml} / \mathrm{hr}$ (series A) or PRCs of 120 to $130 \mathrm{ng} / \mathrm{ml} / \mathrm{hr}$ (series B). These data suggest that the mass of renin cleared per unit time is a linear function of plasma concentration (i.e., clearance is constant) over a wide range of plasma concentrations.

The renin clearance rates measured in these cxpcriments averaged 13 to $16 \mathrm{ml} / \mathrm{kg} / \mathrm{min}$. These values are threefold higher than those reported by Boyd (1979) and Peters-Haefeli (1971); however, it is important to note that both previous studies were performed on anesthetized rats after extensive surgery. The BSP clearances measured in our experiments provided a monitor for changes in hepatic blood flow, but without hepatic a-v differences, actual flows could not be quantified. However, if a $50 \%$ value for the extraction of BSP is assumed (Bradley et al., 1945), the clearance data predict average hepatic plasma flows of 38 to $50 \mathrm{ml} / \mathrm{kg} / \mathrm{min}$. Hematocrits ranged from 40 to $45 \%$, giving hepatic blood flows of 55 to $75 \mathrm{ml} / \mathrm{kg} / \mathrm{min}$. These are very similar to values reported by Birnie and Grayson (1952) for unanesthetized rats. Again, assuming 50\% extraction for BSP and that the liver is the only significant source of renin 
clearance, the ratio of BSP and renin clearances would yield an hepatic extraction ratio of $40 \%$ for renin, a value similar to that reported for rats (Horky et al., 1970) and other species (Heacox et al., 1967; Hesse et al., 1978).

The 30\% fall in BSP clearance observed in the chronic rats between 30 and $75 \mathrm{~min}$ is most likely due to the vasoconstrictor effects of large quantities of circulating AII on hepatic resistance vessels, rather than simply to a spontaneous change over time. In support of this, in experiments with normal rats that received only BSP for the entire 90 -min protocol, BSP clearances fell only $13 \pm 6 \%$ between 30 and $75 \mathrm{~min}$, whereas age-matched controls receiving both BSP and renin demonstrated a $31 \pm 3 \%$ drop in the clearance of BSP during the same interval. BSP clearances did not continue to drop between 75 and 90 min suggesting that the vasoconstriction had reached a steady state. A direct vasoconstrictor effect of AII on hepatic resistance vessels has been demonstrated in dogs (DiSalvo et al., 1973).

We have previously shown that acute iv administration of lead results in a dissociation of plasma AII and PRA (Goldman et al., 1981). If plasma AII levels failed to rise with increasing levels of PRA, this finding might explain the increased PRA observed with 500 ppm lead; since AII is a inhibitor of renin secretion, inappropriately low plasma AII concentrations at a given level of PRA would exert less inhibition on renin secretion, and both renin secretion and PRA would rise until a new steady state was achieved. However, there was no evidence for a decreased AII/ PRA ratio at $500 \mathrm{ppm}$ lead in these experiments, as evidenced by the slope of the regression line for All and PRA in these animals and their controls. In contrast, the rats exposed to $1000 \mathrm{ppm}$ lead did have a lower AII/ PRA ratio than either the control or 500-ppm rats. As previously suggested, this failure of All to increase normally with PRA is due to a lead-induced inhibition of AI conversion to
AII and/or an increased clearance of AII (Goldman et al., 1981). Finally, it should be noted that this phenomenon occurs with much lower doses of lead when exposure to the metal is begun in utero (Victery et al., 1982b).

\section{REFERENCES}

BiRniE, J. H., AND GRAYSON, J. (1952). Observations on temperature distribution and liver blood flow in the rat. J. Physiol. 116, 189-201.

BoYD, G. W. (1979). The prolonged pressor response to renin in the nephrectomized rat. Circ. Res. 45, 396404.

Bradley, S. E., INGelfinger, F. J. Bradley, G. P., AND CURRY, J. J. (1945). The estimation of hepatic blood flow in man. J. Clin. Invest. 24, 890-897.

ChristLieb, A. R., COUCH, N. P., AMSTERDAM, E. A., DOBRZINSKY, S. J., AND HICKLER, R. B. (1968). Renin extraction by the human liver. Proc. Soc. Exp. Biol. Med. 128, 821-823.

DeVito, E., KoninCKX, A., AND CABRERA, R. R. (1974). Circulating life of renin and the sustained pressor principle in normal nephrectomized nd ischemic kidney rats. Acta Physiol. Lat. Amer. 24, 488-492.

DiSalvo, J., Britton, S. Galvas, P., and Sanders, T. W. (1973). Effects of angiotensin I and angiotensin II on canine hepatic vascular resistance. Circ. Res. 32, 85-92.

FLEISCHER, N., MOUW, D. R., AND VANDER, A. J. (1980). Chronic effects of lead on renin and renal sodium excretion. J. Lab. Clin. Med. 95, 759-770.

GOLDMAN, J. M.. VANDER, A. J., MOUW, D. R., KEISER, J.. AND NiCHOLLS, M. G. (1981). Multiple short-term effects of lead on the renin-angiotensin system. J. Lab. Clin. Med. 97, 251-263.

Heacox, R., HaRvey, A. M., AND VANDER, A. J. (1967). Hepatic inactivation of renin. Circ. Res. 21, 149-152.

Hesse, B., Andersen, E. D., and Ring-larsen, H. (1978). Hepatic elimination of renin in man. Clin. Sci. Molec. Med. 55, 377-382.

HoRKY, K., ROJO-ORTEGA, J. M., RODRiguez, J., AND GENEST, J. (1970). Renin uptake and excretion by liver in the rat. Amer. J. Physiol. 219, 387-390.

KeISER. J. A., VANDER, A. J.. AND GERMAin. C. L. (1983). Effects of lead on the secretion and disappearance of renin in rabbits. Toxicol. Appl. Pharmacol. 69, 117126.

Michelakis, A. M., and Mizukoshi, H. (1971). Distribution and disappearance rate of renin in man and dog. J. Clin. Endocrinol. 33, 27-34.

MOUW, D. R., VANDER, A. J., COX, J., AND FleISCHER, N. (1978). Acute effects of lead on renal electrolyte 
excretion and plasma renin activity. Toxicol. and Appl. Pharmacol. 46, 435-447.

Nicholls, M. G., AND EsPiner, E. A. (1976). A sensitive, rapid radioimmunoassay for angiotensin II. N.Z. Med. J. 83, 399-403.

Park, C. S., Malvin, R. L., MurRay, R. D., and Cho, K. W. (1978). Renin secretion as a function of renal renin content in dogs. Amer. J. Physiol. 234, F506F509.

PETERS-HAEFELl, L. (1971). Rate of inactivation of endogenous or exogenous renin in normal and in renindepleted rats. Amer. J. Physiol. 221, 1339-1345.

Schaechtelin, G., Regoli, D., and Gross, F. (1964). Quantitative assay and disappearance rate of circulating renin. Amer. J. Physiol. 206, 1361-1364.

SChNeider, E. G.. Davis, J, O., BAuMber, J. S., AND
JOHNSON, J. A. (1970). The hepatic metabolism of renin and aldosterone. Circ. Re's. S27-S28, I175-183.

SchneIder, E. G., Rostorfer, H. H., and NaSH, F. D. (1968). Distribution volume and metabolic clearance rate of renin in anesthetized nephrectomized dogs. Amer. J. Physiol. 215, 1115-1122.

Seligson, D., Marino, J., and Dodson, E. (1957). Determination of sulfobromophthalein in serum. Clin. Chem. 3, 638-645.

Victery, W., Thomas, D., Schoeps, P., AND VANDER, A. J. (1982a). Lead increases urinary zinc excrction in rats. Biol. Trace Element Res, 4, 211-219.

Victery, W., Vander, A. J., Shulak, J. M., SCHOEPS, P., AND JULIAS, S. (1982b). Lead. hypertension and the renin-angiotensin system in rats. J. Lab. Clin. Med. 99 , $354-362$. 